* Mestranda em Direito pela Universidade Federal de Juiz de Fora (UFJF).

Graduada em Direito em 2016 pela Universidade Federal de Juiz de Fora (UFJF).

Email: elorafernandes@live. com

** Doutor em Direito em 2011 pela Universidade do Estado do Rio de Janeiro (UERJ).

Mestre em Direito em 2006 pela Universidade do Estado do Rio de Janeiro (UERJ).

Especialista em Direito Civil em 2010 Università di Camerino (UNICAM).

Graduado em Direito em 2003 pela Universidade Federal de Juiz de Fora (UFJF).

Email: smcnegri@yahoo.com

\section{Reivindicações Por Justiça e a IDENTIFICAÇÃo de ATINGIDOS NO EIXo Minerário do Projeto Minas-Rio}

Justice Claims AND THE IDENTIFICATION of Affected People in the Mining Axis of The Projeto Minas-Rio

\section{Elora Raad Fernandes* Sergio Marcos Carvalho de Ávila Negri**}

Como citar: FERNANDES, Elora Raad; NEGRI, Sergio Marcos Carvalho de Ávila. Reivindicações por justiça e a identificação de atingidos no eixo minerário do projeto Minas-Rio. Scientia Iuris, Londrina, v. 22, n. 1, p.37-73, mar. 2018. DOI: 10.5433/2178-8189.2018v22n1p37. ISSN: 2178-8189.

Resumo: O presente trabalho pretende analisar o processo de identificação de atingidos no eixo minerário do Projeto Minas-Rio, que compreende os municípios de Conceição do Mato Dentro, Alvorada de Minas e Dom Joaquim, em uma perspectiva de justiça, segundo Nancy Fraser. Realiza-se um estudo de caso com base nos preceitos Robert Yin, segundo o qual seria possível dar início ao desenvolvimento de uma teoria sobre o processo de identificação de atingidos no 
Brasil, que poderá ser replicada e confirmada em outros casos. Conclui-se que injustiças das três dimensões definidas pelo marco teórico foram identificadas ao longo do processo de instalação do empreendimento, quais sejam, as de redistribuição, reconhecimento e representação e que esta última poderia estar obstruindo a busca pela reparação das injustiças de primeira ordem. Neste sentido, através da análise de outros casos de violações de direitos humanos em empreendimentos minerários, seria possível encontrar padrões de comportamento empresarial e estatal que fazem com que o modelo atual de identificação de atingidos tenha de ser revisto.

Palavras-Chave: Projeto Minas-Rio. Identificação de atingidos. Direitos Humanos e empresas.

Abstract: This study analyzes the identification process of the affected people in the mining axis of Projeto Minas-Rio - formed by the cities of Conceição do Mato Dentro, Alvorada de Minas and Dom Joaquim. Moreover, this research stems from Nancy Fraser's perspective of justice and explores this case as an instrument for developing a theory necessary for an effective identification process while still being able to be replicated and confirmed if other cases occur. Furthermore, this paper concludes that injustices from the theoretical framework's three dimensions alongside the 
project's installation process are damaging to a larger social perspective, specifically in the context of injustices from redistribution, recognition and representation and the latter could be obstructing the reparation of first-order injustices. In this sense, through the analysis of other cases of human rights violations in mining enterprises, it is possible to find patterns of business' and state's behavior that causes the need for the current model to be reviewed.

Keywords: Projeto Minas-Rio. Identification of affected people. Business and human rights. 


\section{INTRODUÇÃO}

Tradicionalmente, a linguagem jurídica se estruturou por meio de um processo de abstração. O desprezo pelo concreto mascara, por vezes, filtros institucionalizados que impossibilitam algumas pessoas ou grupos de apresentarem, em condições de paridade com os demais, reivindicações por justiça, contribuindo, assim, com a neutralização e ocultamento dos conflitos sociais. Ao contrário da imagem do sujeito jurídico, delineado abstratamente pelo campo jurídico, existe, em concreto, uma disputa, nem sempre assinalada, pela determinação de quem são efetivamente os verdadeiros titulares de demandas por violações de direitos.

A análise de conflitos e das violações de direitos humanos envolvendo o exercício da atividade de mineração no Brasil pode auxiliar na compreensão desses filtros, que funcionam como verdadeiros obstáculos aos processos de reivindicação por justiça. A determinação das pessoas e comunidades atingidas pela implantação e operação de um empreendimento minerário mostra-se fundamental para o estabelecimento de uma política socialmente responsável e para a mitigação dos danos socioambientais efetivamente causados. Ocorre que, principalmente durante o licenciamento ambiental de empreendimentos minerários, a noção de "atingido" é trabalhada em uma perspectiva restritiva e excludente, como se fosse meramente técnica e econômica.

Esse quadro não é diferente no eixo minerário do "Projeto Minas Rio", atualmente administrado pela Anglo Ferrous Minas-Rio Mineração S.A, caso escolhido para o trabalho em questão. Nessa perspectiva, busca-se analisar, no presente trabalho, como se desenvolveu o processo 
de identificação de atingidos no local, destacando principalmente o nível de participação da própria comunidade na construção da categoria em disputa. Para tal, utiliza-se a metodologia do estudo de caso, segundo os preceitos de Robert Yin (2005).

Como marco teórico, utiliza-se a teoria de justiça de Nancy Fraser, segundo a qual as reivindicações por justiça social podem ser dividias em três dimensões: as reivindicações por redistribuição e por reconhecimento (denominadas pela autora como questões de primeira ordem) e por representação (de segunda ordem). Sua teoria será utilizada como base para subsunção das violações de direitos humanos encontradas ao longo da instalação do empreendimento e posterior definição da justiça no processo de identificação de atingidos por empreendimentos minerários.

A partir do exposto, o presente trabalho se divide em quatro partes. Após a introdução do tema e da abordagem adotada ao longo do trabalho, na primeira parte expõe-se a metodologia utilizada, qual seja, o estudo de caso, segundo proposto por Robert Yin, assim como justificativas e limitações do trabalho. Na segunda, apresenta-se a teoria tridimensional de justiça de Nancy Fraser como marco teórico adotado. $\mathrm{Na}$ terceira seção, discute-se o Estudo de Impacto Ambiental (EIA) como o momento correto de identificação dos atingidos, de acordo com a legislação ambiental, a fim de introduzir a problemática quanto ao processo de identificação de atingidos por empreendimentos minerários. Na quarta parte, apresentam-se as violações de direitos humanos ocorridas ao longo da implantação do empreendimento em seu eixo minerário através de sua subsunção às três dimensões de justiça apresentadas pelo marco teórico, numa tentativa de demonstrar a trivalência do caso aqui narrado e a injustiça no processo de identificação de atingidos por 
empreendimentos minerários. Por fim, nas conclusões finais, retoma-se o exposto ao longo do trabalho e são traçadas conexões com trabalhos futuros.

\section{ESTRATÉGIAS METODOLÓGICAS}

A metodologia a ser aqui utilizada é o estudo de caso, conforme os preceitos de Robert Yin (2005). Segundo o autor, os estudos de caso, em geral, são originados de perguntas de pesquisa do tipo "como" e "por que", "quando o pesquisador tem pouco controle sobre os acontecimentos e quando o foco se encontra em fenômenos contemporâneos inseridos em algum contexto da vida real" (YIN, 2005, p. 19). Esse tipo de estudo, portanto, permite investigar um caso preservando características significativas da vida real, características estas tão complexas que uma estratégia experimental ou mesmo um levantamento não seriam suficientes para abarcar.

O método do estudo de caso pode ser utilizado de diversas maneiras e, neste trabalho, ele será empregado como uma forma de iniciar uma generalização de teorias. Segundo Yin (2005), uma das maiores preocupações quanto aos estudos de caso é que eles fornecem pouca base para generalizações científicas. Ocorre que estes, na verdade, são generalizáveis a proposições teóricas e não a populações ou universos, ou seja, a lógica a ser aplicada é a da replicação e não a da amostragem (generalização analítica e não generalização estatística).

Nesta linha, busca-se responder como se desenvolveu o processo de identificação das pessoas atingidas pelo eixo minerário do Projeto Minas-Rio, no que se refere à justiça do procedimento. Como hipótese, acredita-se que tal processo produziu várias formas de injustiça, ao violar 
diversos direitos humanos da comunidade atingida e produzir obstáculos políticos que impediram a participação da população em condição de paridade com os demais atores evolvidos.

A fim de se seguir o critério de qualidade denominado validade do constructo (YIN, 2005), buscou-se fontes múltiplas de evidência. Posto que esta metodologia é utilizada quando o pesquisador possui pouco controle sobre os eventos do caso, sendo estes predominantemente contemporâneos, analisou-se dados indiretos sobre o empreendimento, como relatórios produzidos sob a perspectiva dos atingidos e documentos oficiais derivados do processo de licenciamento do empreendimento.

Como unidade de análise do caso, o marco temporal utilizado é definido pelo início da discussão sobre o licenciamento, no ano de 2006 até a concessão da Licença de Operação, no final de 2014. Espacialmente, escolheu-se estudar a identificação de atingidos no eixo minerário do empreendimento, que compreende as cidades de Conceição do Mato Dentro, onde se encontra a grande mina Sapo-Ferrugem, Alvorada de Minas, onde se situa a estação de beneficiamento do minério e Dom Joaquim, onde se localiza o Rio Peixe, que fornece água para o empreendimento.

Cabe ressaltar os limites metodológicos enfrentados, uma vez que o estudo de apenas um caso pode não fornecer uma base tão sólida para o estabelecimento de teorias. Ademais, a riqueza de detalhes de um caso que já dura mais de dez anos não pode ser completamente descritas, de modo que aqui se encontram as passagens mais importantes no tocante à identificação e à tutela dos direitos dos atingidos pelo empreendimento. Assim, esse estudo pretende ser o início de uma análise mais ampla e profunda de outros casos semelhantes. Em trabalhos futuros, ao se coletar informações sobre outros empreendimentos minerários, um 
padrão de comportamento pode ser encontrado, de maneira a possibilitar o estabelecimento de uma teoria sobre a identificação de atingidos por empreendimentos minerários no Brasil.

\section{FRASER E A TEORIA DE JUSTIÇA TRIDIMENSIONAL}

O substrato teórico deste trabalho tem como base a teoria de justiça tridimensional de Nancy Fraser (2006, 2009) e Fraser e Honneth (2003). Segundo a autora, no mundo de hoje, reinvindicações por justiça social, no que concerne a questões de primeira ordem (substanciais), parecem estar divididas em dois tipos. Primeiramente, existem as reivindicações redistributivas, que buscam uma distribuição mais justa dos recursos e riquezas. Em segundo lugar, têm-se as reivindicações de reconhecimento, voltadas para o respeito das diferenças, a partir das quais se busca um caminho em que a assimilação às normas culturais dominantes não seja mais o preço a ser pago pelo respeito. Além desses dois tipos de reivindicações, há ainda questões de segunda ordem acerca da estrutura apropriada a ser considerada para essas reivindicações substantivas, incorporando-se a dimensão política da representação.

Em relação às injustiças de primeira ordem, que geram reivindicações por redistribuição e reconhecimento, estas, em um primeiro momento, podem parecer contrastantes, uma vez que a) assumem diferentes conceitos de justiça; b) necessitam de remédios diferentes para que sejam solucionados (reestruturação econômica v. mudança cultural ou simbólica, respectivamente); c) abarcam diferentes concepções de coletividade que sofrem a injustiça (classes ou coletividades similares a classes $v$. grupos de status); d) possuem entendimentos diversos do que seriam diferenças de grupo, pois no paradigma da redistribuição, tais 
diferenças seriam injustas, sendo o resultado socialmente construído de uma política econômica injusta e, no paradigma do reconhecimento, buscar-se-ia chamar atenção para a especificidade de um grupo e a sua diferenciação.

Ocorre que o chamado dilema da redistribuição-reconhecimento é, na verdade, uma falsa antítese. Apesar de poderem ser abstratamente e em casos específicos discutidas de maneira separada, não podendo ser subsumidas entre si, as lutas pela redistribuição e pelo reconhecimento formam duas facetas de uma mesma justiça. Nesse aspecto, não se pode esquecer que nem todas as formas de não-reconhecimento são um produto da má-distribuição e, tampouco, as teorias de reconhecimento podem abarcar problemas com distribuição. Isso é facilmente percebido caso a questão seja colocada em um espectro. Em um extremo estão os casos que se encaixam no paradigma da redistribuição (onde estaria uma divisão social típica, enraizada na estrutura econômica da sociedade) e, no outro, os que se encaixam no do reconhecimento (em que estaria uma divisão típica do paradigma do reconhecimento, baseada em uma ordem social de status, opostamente à estrutura econômica).

A questão fica mais turva, porém, ao considerarmos as coletividades localizadas na região intermediária, onde encontramos tipos híbridos que combinam características de ambas as reivindicações. Essas são as chamadas coletividades bivalentes que sofrem, portanto, injustiças que remontam às duas dimensões, de forma que nenhuma delas seja efeito indireto da outra (exemplo disso seriam os problemas de gênero). Nota-se, assim, que não é possível ater-se ao reducionismo de considerar apenas um remédio para cada coletividade, de forma que o objetivo deve ser desenvolver uma abordagem integrada que englobe e harmonize tais facetas da justiça em uma única estrutura normativa. 
O núcleo normativo dessa concepção é a noção de paridade de participação: de acordo com tal norma, a justiça requer arranjos sociais que permitam que todos interajam um com os outros como pares. Superar injustiças, portanto, significa retirar os obstáculos institucionalizados que impedem que alguns sujeitos participem em condições de paridade com os demais, como parceiros integrais de interação social.

Além das dimensões acima apresentadas, esta noção também é núcleo normativo da terceira dimensão da justiça, segundo Fraser (2009), qual seja, a representação. Segundo a autora, durante muito tempo as questões de justiça foram discutidas em um enquadramento KeynesianoWestfaliano, ou seja, dentro do Estado nacional. Com a globalização, esse enquadramento pode ser produtor de injustiças políticas, uma vez que nele não se discute o "quem" e o "como" da justiça, questões cruciais nos tempos atuais em que organizações e empresas transnacionais geram discussões que transcendem as fronteiras do Estado. Discute-se apenas o "que" da justiça, ou seja, o que deve ser reparado.

Analisando a questão em níveis de pertencimento e procedimento, a representação é uma questão de pertencimento social no que diz respeito a um primeiro nível, que está ligado à definição de fronteiras do político, isto é, trabalha-se "a inclusão ou a exclusão da comunidade formada por aqueles legitimados a fazer reivindicações recíprocas de Justiça” (FRASER, 2009), o que pode levar a uma injustiça de mau enquadramento. De outro modo, a regra decisória, em um segundo nível, "diz respeito aos procedimentos que estruturam os processos públicos de contestação" (FRASER, 2009), que podem levar a injustiças de falsarepresentação política-comum.

Face à globalização é crucial, portanto, mudar as fronteiras do "quem" da justiça e o modo de sua constituição ("como"), a fim de que 
se superem as injustiças do mau enquadramento. Para tanto, a autora adota uma política transformativa que reivindica novo enquadramento aos debates sobre justiça, devendo esta obedecer não mais ao "espaço dos lugares, mas ao espaço dos fluxos" (FRASER, 2009, p. 28). Quando, porém, se falha em institucionalizar a paridade de participação no nível metapolítico, deve-se passar a discutir a própria democratização do processo de estabelecimento do enquadramento, de forma que as lutas por justiça em um mundo globalizado não podem obter sucesso se não caminharem em conjunto com as lutas por democracia metapolítica.

\section{O ESTUDO DE IMPACTO AMBIENTAL E O PROCESSO DE IDENTIFICAÇÃO DE ATINGIDOS}

O licenciamento ambiental foi criado como um instrumento institucional para o controle e avaliação da sustentabilidade de atividades humanas que interferem nas condições socioambientais. Pensado como uma forma de se buscar um melhor equilíbrio entre o desenvolvimento econômico e a utilização dos recursos naturais, revela-se, por vezes, como um procedimento insuficiente para uma efetiva avaliação da viabilidade socioambiental de determinados empreendimentos.

No Brasil, segundo a Resolução no 237 de 1997 do Conselho Nacional do Meio Ambiente (CONAMA, 1997), o processo de licenciamento ambiental é repartido em três fases: a Licença Prévia, que aprova a sua localização e concepção e estabelece requisitos e condicionantes a ser atendidos nas próximas fases de implementação; a Licença de Instalação, que autoriza a instalação do empreendimento "de acordo com as especificações constantes dos planos, programas e projetos aprovados, incluindo as medidas de controle ambiental e demais 
condicionantes, da qual constituem motivo determinante" (CONAMA, 1997) e a Licença de Operação, que autoriza a "operação da atividade ou empreendimento, após a verificação do efetivo cumprimento do que consta das licenças anteriores, com as medidas de controle ambiental e condicionantes determinados para a operação" (CONAMA, 1997).

Instrumento previsto na Constituição brasileira, em seu Art. $225, \S 1^{\circ}$, Inciso IV, o EIA “é um documento de natureza técnica, que tem como finalidade avaliar os impactos ambientais gerados por atividades e/ou empreendimentos potencialmente poluidores ou que possam causar degradação ambiental". Ele deve trazer, também, medidas mitigadoras e de controle ambiental, com o objetivo de garantir o uso sustentável dos recursos naturais (BRASIL, 2009).

Segundo a Resolução n ${ }^{\circ} 001$ (CONAMA, 1986), a elaboração do EIA e seu respectivo Relatório de Impacto Ambiental (RIMA) é obrigatória em determinados licenciamentos. Estas hipóteses estão elencadas em seu art. $2^{\circ}$ e uma delas, presente no inciso IX, é a "Extração de minério, inclusive os da classe II, definidas no Código de Mineração" (CONAMA, 1986). O órgão competente para o licenciamento pode ainda fixar, com base nas diretrizes da resolução, indicações adicionais que, pelas peculiaridades do projeto e características ambientais da área, forem julgadas necessárias através de um Termo de Referência.

A Resolução 001/86 (CONAMA, 1986) estabelece que o EIA deve ser realizado por equipe multidisciplinar habilitada, que deverá ser responsável tecnicamente pelos resultados apresentados, e deve apresentar, no mínimo, quatro atividades técnicas, elencadas em seu art. $6^{\circ}$. Dentro da primeira atividade técnica exigida pela resolução, qual seja, o diagnóstico ambiental da área de influência do projeto, com uma descrição detalhada dos recursos ambientais e suas interações, além de 
considerar-se o meio físico (alínea a) e o meio biológico e os ecossistemas naturais (alínea b), é necessário diagnosticar o meio socioeconômico, que contemplaria:

[...] o uso e ocupação do solo, os usos da água e a sócio-economia, destacando os sítios e monumentos arqueológicos, históricos e culturais da comunidade, as relações de dependência entre a sociedade local, os recursos ambientais e a potencial utilização futura desses recursos. (CONAMA, 1986).

Ademais, o art. $5^{\circ}$ da resolução, em seu inciso III, dispõe que o EIA deverá “definir os limites da área geográfica a ser direta ou indiretamente afetada pelos impactos, denominada área de influência do projeto, considerando, em todos os casos, a bacia hidrográfica na qual se localiza" (CONAMA, 1986). É exatamente no momento de elaboração do EIA, portanto, que os atingidos devem ser identificados, justamente porque nele são descritas todas as mudanças socioeconômicas e ambientais a ser sofridas na região.

Todas as despesas referentes à realização do Estudo de Impacto Ambiental deverão correr por conta do proponente do projeto (CONAMA, 1986). Percebe-se, de tal forma, que a equipe responsável pela elaboração do estudo é contratada pelo próprio interessado na concessão da licença, o que pode gerar conflitos. Conforme destaca Zhouri (2008), o papel desempenhado pelas empresas de consultoria ambiental compromete a própria transparência do processo, uma vez que, seguindo a lógica do mercado, elas tendem a "elaborar estudos que não inviabilizem o projeto dos contratantes" (ZHOURI, 2008, p. 102).

Existem também problemas no que se refere à previsão legal da participação popular na elaboração do EIA. A realização de audiência 
pública não é obrigatória e, segundo Resolução 009/87 (CONAMA, 1987), em seu art. $2^{\circ}$, apenas será realizada quando o órgão de meio ambiente julgar necessário ou quando for solicitado por entidade civil, pelo Ministério Público, ou por cinquenta ou mais cidadãos. A ata de tal audiência servirá de base, juntamente com o RIMA, para a análise e parecer final do licenciador quanto à aprovação ou não do projeto, segundo art. $5^{\circ}$ da Resolução (CONAMA, 1987).

Ademais, a resolução traz apenas a possibilidade da realização de audiências públicas para conhecimento do projeto e seus impactos e para a discussão do RIMA. A participação popular se concretiza, assim, tardiamente, com o relatório já produzido e com decisões já realizadas. Apoiados em uma linguagem técnica, os relatórios são confirmados sem que os questionamentos feitos pela comunidade sejam respondidos, o que transforma a participação popular em simples forma de "legitimação de um processo previamente definido" (ZHOURI, 2008, p. 103).

\section{O PROCESSO DE IDENTIFICAÇÃO DE ATINGIDOS NO EIXO MINERÁRIO DO PROJETO MINAS-RIO}

\subsection{Aspectos gerais do projeto}

Segundo Barcelos (2014), o Projeto Minas-Rio pode ser considerado o maior empreendimento mineiro-portuário do mundo e está configurado em dois trechos: o trecho em Minas Gerais, que inclui a fase da exploração, tratamento e transporte mineral, além da planta industrial de beneficiamento e tratamento de minério, e o trecho fluminense que é composto pela continuação do mineroduto, pelo Complexo Industrial e Portuário do Açu, com linhas de transmissão entre o empreendimento e a Furnas, e por um corredor logístico ligando o empreendimento à BR-101. 
Este projeto se efetivou através da congregação de interesses econômicos regionais-globais dos governos de Minas Gerais, do governo do Rio de Janeiro e do Grupo EBX, do empresário Eike Batista, o que expressa a capilaridade do setor privado no desenrolar dos programas e políticas estatais. Em janeiro de 2008, a mineradora Anglo American adquiriu todos os direitos dos projetos Minas-Rio e Amapá até então pertencentes à MMX - Mineração e Metálicos S.A. Para tanto, foi realizada a cisão parcial da mineradora controlada por Eike Batista. A restruturação da MMX não promoveu, contudo, a completa separação dos projetos. Mesmo sendo uma sociedade distinta, com personalidade jurídica própria, a Anglo, por meio das suas controladas, participa, ainda que indiretamente, de aspectos importantes do projeto do complexo portuário

A cisão parcial da MMX e a transferência dos direitos do Projeto Minas-Rio induzem a fragmentação, mas não podem ser utilizadas para apagar os traços da conexão inicial entre os projetos, que ainda persistem. Isso ocorre porque toda a restruturação societária foi realizada, segundo o receituário padrão, conjuntamente com a formalização de novas alianças e conexões. Mesmo assim, como acontece com os grandes empreendimentos de infraestrutura existe, para fins de responsabilização, uma tentativa de completa fragmentação dos projetos.

Várias estratégias são utilizadas com essa finalidade. A primeira, e geralmente a mais importante, diz respeito à indevida separação dos processos de licenciamento ambiental, prejudicando, assim, a análise dos impactos causados. Não verdade, a fragmentação se transforma, por vezes, em estratégia jurídica para dificultar a responsabilização das sociedades empresárias envolvidas no empreendimento.

A partir desse panorama, neste tópico será feita uma análise 
do processo de identificação de atingidos ocorrido na fase minerária do Projeto Minas-Rio, com base na teoria de justiça de Nancy Fraser. Ao que se parece, o que ocorreu no caso do Projeto Minas-Rio, no que concerne à mina de minério de ferro e suas estruturas adjacentes, foram injustiças referentes às três dimensões tratadas pela autora, como se explicará a seguir. Assim, escolheu-se dividir este tópico a partir da subsunção dos dados encontrados sobre o empreendimento às três dimensões de justiça desenvolvidas pelo marco teórico: os dois primeiros pontos relacionados às reivindicações por justiça de primeira ordem (substanciais), quais sejam, por redistribuição e por reconhecimento e o terceiro item concernente às reivindicações por justiça de segunda ordem, isto é, por uma adequada representação.

Ressalta-se uma limitação metodológica quanto a essa divisão, pois, como já reforçado anteriormente, mesmo que autônomas, essas facetas são interligadas, não podendo ser divididas de forma estanque. As violações serão discutidas em cada item de acordo com a predominância de cada dimensão de justiça. A descrição das violações será importante para que se perceba de que maneira a comunidade foi atingida. A ênfase, porém, será dada na dimensão política, uma vez que se acredita que esta deve ser a primeira a ser solucionada, pois esta pode obstruir a promoção da justiça e reparação dos direitos humanos referentes às injustiças de primeira ordem.

\subsection{As injustiças de redistribuição}

A dimensão redistributiva da justiça está ligada à estrutura econômica da sociedade e diversas injustiças desse tipo podem ser verificadas no caso em estudo. Exemplos como a privação, isto é, não 
ter acesso a um mínimo existencial de bens e a marginalização, que ocorre quando pessoas são obrigadas a exercer um trabalho indesejado (FRASER, 2006), são flagrantes.

Como destaca Coelho (2015), a mineração tem relação direta com o subdesenvolvimento, sendo que, por vezes, até mesmo o aprofunda ao reproduzir estruturas de concentração de renda e exploração de trabalhadores em "circuitos econômicos exclusivos e, por isso, excludentes das populações locais, principalmente de grupos de baixa renda" (COELHO, 2015, p. 57).

$\mathrm{O}$ avanço da mineração e da exploração de recursos naturais envolve também disputas por terra e pelos recursos a ela agregados. Assim como aconteceu em outras regiões, a concepção do Projeto Minas-Rio passa, necessariamente, pela expropriação do território de pequenos agricultores e da comunidade local. Nas complexas operações de restruturação societária, transferência de ativos e alteração de nomes que envolveram a MMX e a Anglo, não se pode deixar de ressaltar a presença de uma sociedade subsidiária, a Borbagato Agropastoril S.A.("Borbagato").

Controlada inicialmente pela MMX, a Borbagato tem como objeto social, a compra, venda, locação, e/ou arrendamento de terrenos e imóveis em áreas urbanas e rurais. A sociedade em questão esteve envolvida na polêmica aquisição de terrenos na região do Projeto MinasRio para a MMX, antes da divulgação do interesse da sua controladora na construção do empreendimento. A estratégia envolvia uma abordagem violenta dos moradores para que vendessem seus terrenos, diante da inexorabilidade da obra (SANTOS, 2009 apud BARCELOS, 2014). Os valores pagos pelos terrenos eram irrisórios, as moradias de diversas famílias eram tomadas e dava-se início ao processo de desmobilização 
dos atingidos, pois a empresa lidava com cada família em separado a fim de "negociar" as propriedades.

Ressalta-se, também, que diante do acordo já mencionado entre o governo do estado de Minas Gerais e a sociedade empresária, diversas desapropriações por utilidade pública realizadas pela administração para a construção das minas e dos dutos foram decretadas. Foram desapropriadas as terras necessárias “à construção das instalações complementares ao empreendimento mineroduto Minas-Rio e à implantação das minas de minério de ferro e da usina de beneficiamento, localizadas nos municípios de Conceição do Mato Dentro e Alvorada de Minas respectivamente" (REPRESENTAÇÃO MPF, 2012, p. 3 apud BARCELOS, 2014, p. 56). Além do preço pago pela terra que, constantemente, era alvo de conflitos e demandas judiciais, há relatos de que "as terras adquiridas eram cercadas e os moradores impedidos de por elas circular, o que impedia a continuidade do uso coletivo e o acesso à água." (BARCELOS, 2014, p. 54).

Apesar dos diversos problemas fundiários e dos questionamentos contrários à instalação do empreendimento no local, a Licença Prévia foi concedida pelo órgão ambiental, em dezembro de 2008, com 78 condicionantes. Tal decisão pode ter sido influenciada pelo fato de as licenças da mina, do mineroduto e do complexo industrial do porto terem corrido separadamente e em órgãos diferentes. Como as Licenças Prévias do mineroduto e do porto de Açu já haviam sido concedidas em 2007, o licenciamento da mina passou a ser indispensável para o funcionamento das fases já licenciadas (GUSTIN, 2015).

Em parecer único da SISEMA, esta determina que, entre a Licença Prévia e a Licença de Instalação, deveriam "ser apresentados 
os resultados do Cadastro Patrimonial e Social, as minutas de acordo com cada categoria de atingido, e os anteprojetos de reassentamento" (MINAS GERAIS, 2008), uma vez que foram detectadas falhas no EIA/ RIMA quanto à delimitação do meio ambiente a ser atingido e a omissão de diversas comunidades na caracterização da Área Diretamente Afetada (ADA), da Área de Influência Direta (AID) e da Área de Influência Indireta (AII).

Em março de 2009, o empreendedor solicitou ao SISEMA a Licença de Instalação da lavra na região. Já que diversas condicionantes da Licença Prévia não haviam sido cumpridas, a Secretaria de Estado de Meio Ambiente e Desenvolvimento Sustentável (SEMAD) fragmentou o licenciamento em duas fases: a fase 1 seria vinculada às condicionantes já cumpridas e a fase 2 às condicionantes não cumpridas (ZHOURI, 2014 apud GUSTIN, 2015). Ressalta-se que, como previsto na Resolução $\mathrm{n}^{\circ} 237$ de 1997 do CONAMA (CONAMA, 1997), o cumprimento das condicionantes é condição sine qua non para concessão de novas licenças. Verifica-se, portanto, o descumprimento pelo poder público de tal norma, que concedeu verdadeiro "perdão" à empresa por todas as violações cometidas até esse momento.

Em dezembro de 2009 a primeira fase da licença foi concedida, estabelecendo-se ainda mais condicionantes. Uma delas, no que toca ao demandado pela comunidade em relação ao Programa de Negociação Fundiária, seriam as diretrizes gerais de reassentamento em que se estabelecia que, "em termos de área, infraestrutura, viabilidade agrícola e demais direitos sociais e produtivos atenderá, no mínimo, às diretrizes aprovadas pelo COPAM para o reassentamento da UHE Irapé." (SEMAD, 2009, p. 14 apud BECKER; PEREIRA, 2011).

Segundo Becker e Pereira (2011), em abril de 2010, a Anglo 
Ferrous Minas-Rio Mineração S.A. encaminhou à SUPRAM uma proposta de complementação dos dados socioeconômicos, porém foi manifestada discordância pelos atingidos em relação ao modelo de cadastramento apresentado, pois este não abarcava sua totalidade. A Comissão dos Atingidos, criada com o fim de fiscalizar esse processo, protocolou um documento na SUPRAM Jequitinhonha denominado "Solicitação de complementação do cadastro dos atingidos em situação emergencial da Anglo Ferrous Brazil", em que se alegava diversas falhas na identificação de atingidos (PRATES, 2014, p. 35). Após a 43 ${ }^{\text {a }}$ Reunião da URC Jequitinhonha, em que se discutiram as questões contidas no documento protocolado, foi acordado que a empresa custearia novo laudo confeccionado por empresa independente, dentre três a ser indicadas pela Comissão de Atingidos (PRATES, 2014).

Em agosto de 2011, o laudo de caracterização da área foi apresentado pela empresa Diversus. Na questão do reassentamento, verificou-se a não consideração das decisões da SUPRAM de utilizar como referência o TAC (Termo de Ajustamento de Conduta) de Irapé de maneira que a equipe da Diversus (2011) recomendou, entre outras medidas, a suspensão do empreendimento, enquanto não fosse resolvida a situação dos atingidos emergenciais; o reassentamento das famílias apenas quando cumpridas devidamente as cláusulas das negociações; a garantia de uma mudança saudável das famílias; o pagamento de todas as custas necessárias para a mudança e a revisão do Programa de Negociação Fundiária para se adequar ao TAC Irapé etc. Entretanto, em adendo produzido pela Diversus um ano após a publicação do diagnóstico, uma nova pesquisa revelou que tais problemas continuavam sem solução (DIVERSUS, 2012 apud PEREIRA; BECKER; WILDHAGEN, 2013).

Além de serem utilizados como moradia, os terrenos comprados 
ou desapropriados eram destinados ao próprio sustento daquelas famílias e movimentavam o mercado agrícola da região. Essa situação foi ainda agravada pelo êxodo rural ocorrido após tais acontecimentos, fato completamente atenuado pelo EIA/RIMA e desconsiderado nas discussões sobre as licenças posteriores. Aqueles que conseguiram ficar também foram prejudicados, uma vez que foram privados do meio social que possibilitava o seu sustento. Por fim, além da utilização do aparato estatal para fins privados e do dinheiro público para a mitigação de direitos da população em função dos lucros da empresa, há ainda a apropriação dos bens naturais que antes eram de uso comunitário, o que também caracteriza a privação.

Após essa análise, verificam-se, em vários momentos da história do empreendimento, injustiças de ordem econômica, ou seja, de redistribuição. O caso do Projeto Minas-Rio não representa, porém, uma situação isolada, inserindo-se, na verdade, em uma lógica criada por um “paradigma neoextrativista” (MILANEZ; SANTOS, 2013). Esse modelo é responsável pela replicação dessa injustiça retratada em outros casos, na medida em que promove um processo de distribuição desigual dos recursos e dos riscos ambientais.

Nesse sentido, as comunidades locais tendem a arcar com a maioria dos impactos negativos, enquanto que grande parte dos benefícios é concentrada pelas empresas, ou pelos governos nacionais, caracterizando um grande desequilíbrio na distribuição dos benefícios e prejuízos gerados (MILANEZ; SANTOS, 2013, p. 131).

Não há a paridade participativa sem um patamar mínimo de bens necessários e, consequentemente, sem justiça distributiva. Para que essas injustiças econômicas possam ser afastadas, segundo Fraser (2006) 
seria necessária uma completa reestruturação econômica, pautada na reorganização da divisão do trabalho e na transformação das estruturas econômicas básicas, com uma melhor redistribuição de renda entre outras reformas.

\subsection{As injustiças de reconhecimento}

As questões que agora passam a ser apresentadas têm sido discutidas em casos como este apenas recentemente. Nesse sentido, é de grande contribuição relembrar como a discussão sobre o conteúdo do termo atingido se deu no Brasil. Tal discussão se remonta à década de 1970, época de construção de hidrelétricas, principalmente devido à crise energética mundial da época. O Movimento de Atingidos por Barragens (MAB) foi o grande responsável por cunhar o termo e lutar para que tais processos fossem operados com justiça.

A partir de Vainer (2003), tem-se um panorama de como o tema foi sendo tratado no país. Segundo o autor, por longo tempo operou-se, no Brasil, com a concepção territorial-patrimonialista do atingido, isto é, o atingido era tido como o proprietário de terras a ser utilizadas pelo empreendimento. A perspectiva era indenizatória e o objetivo da ação do empreendedor era a aquisição do domínio das terras. Isso era feito através da desapropriação das mesmas a partir do reconhecimento da utilidade pública do negócio e não se reconhecia a existência de impactos sociais ou ambientais.

Outra concepção que de certa maneira ainda é utilizada, de acordo com Vainer (2003), é a noção do atingido como inundado (no caso de atingidos por empreendimentos hidrelétricos) e, por decorrência, como deslocado compulsório. Apesar de não contar apenas aqueles 
atingidos que possuem a propriedade de sua terra, essa concepção ainda se assemelha bastante à territorial-patrimonialista, pelo mesmo motivo de prevalecer "a estratégia exclusiva de assumir o domínio da área a ser ocupada pelo projeto, e não a responsabilidade social e ambiental do empreendedor" (VAINER, 2003, p. 4).

$\mathrm{O}$ que se percebe nesta situação que se assemelha com o caso aqui descrito é que, em relação àqueles que são considerados atingidos pelo empreendimento, em nenhum momento leva-se em consideração a natureza política, cultural, econômica e ambiental do problema (VAINER, 2003). O que ocorre na região não pode ser resumido a questões patrimoniais, sendo a situação muito mais complexa. Assim, ao se ressaltar e tentar remediar parcialmente apenas as injustiças de redistribuição geradas, esquece-se daquelas criadas pelo não reconhecimento. A relação das pessoas com a terra vai além do local de moradia e de sustento, sendo, na verdade, o local onde por anos seus antepassados viveram, onde são definidas raízes religiosas, onde foram estabelecidos vínculos de amizade e comunidade, que serão desfeitos com o mero pagamento pela propriedade ou o seu reassentamento. $\mathrm{O}$ que não se discute, porém, é que tais práticas não são passíveis de monetização.

No caso concreto, verifica-se, principalmente, a dominação cultural, que é ser submetido a padrões de interpretação e comunicação associados a outras culturas e o desrespeito, que seria a desqualificação ou difamação de alguém durante a interação social (FRASER, 2006).

Em relação à dominação cultural, o discurso do desenvolvimento, a abordagem violenta, justificada pela pressa do mercado global, o modelo de destruição da natureza e da apropriação dos bens comunitários para fins individuais prevalecem sobre os modos de vida da região. E esse foi o motivo pelo qual, em 2011, um novo estudo sobre a comunidade foi 
requisitado, como já acima exposto, e entregue pela Diversus.

Como destacado pela Diversus (2011), toda riqueza antropológica do local foi reduzida a números no EIA/RIMA fornecidos pela empresa. Neste documento constava que os impactos do empreendimento seriam mínimos, uma vez que representavam somente $1,4 \%$ da área ocupada com lavouras e pastagens em toda a AID. Não se procurou saber quem eram, como viviam e o que sofreriam as pessoas impactadas nestes “'irrisórios' 1,4\% de área 'produtiva' dos municípios de Conceição do Mato Dentro e Alvorada de Minas, nem tampouco como estes impactos poderiam ser evitados, minimizados ou compensados" (DIVERSUS, 2011, p. 308).

$\mathrm{Na}$ verdade, todos os prejuízos e impactos relativos ao meio antrópico "foram subsumidos junto com a população existente na área e se transformaram em uma mínima 'redução da área produtiva' acarretando na redução da produção leiteira para fabricação de queijo e na redução da produção para subsistência" (DIVERSUS, 2011, p. 308).

Além da dominação cultural, destaca-se o desrespeito, que também é uma forma da injustiça cultural, que pode ser exemplificado com a marginalização sofrida por aqueles atingidos que são contra a instalação do empreendimento e, por isso, são vistos por uma parcela da comunidade local como verdadeiros obstáculos ao progresso (DIVERSUS, 2011).

Após o relato focado destas violações, verifica-se que no empreendimento, também, foram identificadas injustiças de reconhecimento. A fim de que haja uma superação de cada uma dessas violações apresentadas, é necessário que ocorra uma mudança cultural ou simbólica, que envolve, necessariamente, o reconhecimento e a valorização positiva da diversidade cultural, a revalorização das identidades desrespeitadas e dos produtos culturais dos grupos difamados 
ou, ainda, uma "transformação abrangente dos padrões sociais de representação, interpretação e comunicação, de modo a transformar o sentido do eu de todas as pessoas." (FRASER, 2006, p. 2).

\subsection{As injustiças de representação}

Por fim, discute-se as injustiças de representação sofridas pela comunidade atingida, ou seja, aquelas relativas ao palco político em que as lutas por distribuição e reconhecimento foram conduzidas. Para que elas sejam detectadas, é necessário verificar se as fronteiras da comunidade política excluíram equivocadamente alguns dos titulares do direito à representação e se as regras decisórias da comunidade atribuem a todos os seus membros capacidade igualitária de expressão nas deliberações públicas e representação justa no processo público de tomada de decisão (FRASER, 2009).

Em primeiro lugar, há as injustiças referentes ao mau enquadramento, ou seja, aquelas que concernem ao modo como as fronteiras da comunidade são traçadas, excluindo de alguns indivíduos todas as chances de participarem sobre debates de justiça. No caso concreto, isso ocorre desde a apresentação do EIA/RIMA, a partir do qual várias comunidades foram excluídas pelo empreendedor da qualidade de atingidas.

Além das injustiças de mau enquadramento, percebe-se que aqueles que foram identificados como atingidos não puderam participar de forma paritária na discussão sobre as violações de primeira ordem, sendo esta denominada pela autora como injustiça de falsa-representação política-comum, que ocorre quando as regras do processo político impedem equivocadamente a participação paritária de atores que 
formalmente contam nessa tomada de decisão.

Como pôde ser percebido durante o debate sobre as injustiças de redistribuição feito anteriormente - pois, como já dito, essa divisão não pode ser estanque - a desarticulação do movimento na comunidade vinha sendo feita desde o início do projeto, através das negociações individuais entre a empresa e alguns atingidos e tal comportamento permaneceu ao longo da instalação do empreendimento. Esse processo gera "o fim destas comunidades enquanto tal, passando cada família a se inserir em outras localidades ou na periferia de áreas urbanas, como sedes de municípios ou de distritos da região" (DIVERSUS, 2011, p. 311).

Após a entrega do EIA/RIMA pelo empreendedor para que os documentos fossem discutidos, foi requisitada uma audiência pública por diversas entidades. Em atendimento a esse requerimento, foram realizadas três audiências públicas nas cidades consideradas afetadas: Conceição do Mato Dentro, Alvorada de Minas e Dom Joaquim (MINAS GERAIS, 2008).

Segundo o parecer único da SISEMA(MINAS GERAIS, 2008), no total das três audiências, mais de 2000 pessoas participaram e foram registradas inúmeras manifestações em relação às violações de direitos humanos já discutidas nos tópicos anteriores. O mesmo documento registra que, formalmente, as respostas do empreendedor a essas questões foram apresentadas ao órgão licenciador, mas nada menciona sobre uma solução dada às preocupações dos próprios atingidos, que permaneciam alheios ao que estava ocorrendo em sua própria região.

Mesmo após todas as questões levantadas em audiência, que permaneceram sem resposta, a Licença Prévia foi concedida e, em março 
de 2010, criou-se a Comissão dos Atingidos. Ela foi criada a fim de que se acompanhasse o cumprimento das condicionantes estabelecidas ao se conceder a Licença Prévia e cobrar do Estado uma postura mais firme em relação à empresa.

A partir da proposta de complementação do cadastro de atingidos pela empresa, a Comissão de Atingidos manifestou discordância em relação ao modelo de cadastramento apresentado. Ademais, ressaltaram uma decisão anterior de que não deveriam ser mais os atingidos divididos em atingido direta ou indiretamente, uma vez que seria muito difícil o estabelecimento de tal relação. Contestaram ainda a não inclusão da comunidade de Água Quente na nova categoria criada pela empresa de "atingidos emergenciais".

Essas discussões levaram a uma maior fragmentação do movimento dos atingidos, tendo em vista que a divisão entre atingidos emergenciais ou não, e atingidos direta ou indiretamente criou um atrito entre a comunidade, já que a gravidade do problema pelo qual cada uma das famílias passava é altamente subjetivo. Através dessa divisão, a negociação com os atingidos também era feita de modo separado, "representando prejuízos sociais, materiais e simbólicos quando comparados às recentes negociações feitas já sobre o modelo do TAC Irapé" (DIVERSUS, 2011).

A ausência de informações aprofundadas sobre a dimensão do empreendimento e sobre quem seria realmente afetado pelo projeto foi considerada pela Comissão formada como inadmissível e inconstitucional, uma vez que um empreendimento, que já se encontrava na fase Licença de Instalação 1, não deveria conter apenas ilações ou dúvidas sobre "possíveis" atingidos (COMISSÃO DOS ATINGIDOS apud BECKER; PEREIRA, 2011). 
A discussão acerca de a Comunidade de Água Quente ser emergencial ocorreu durante todo o ano de 2010. Após a validação do cadastro dessa comunidade, e, apesar de todas as adversidades e empecilhos, a Licença de Instalação fase 2 foi concedida, assim que "o histórico de arrolamento das condicionantes que viriam a garantir a qualidade de vida das comunidades atingidas é mantido" (BECKER; PEREIRA, 2011, p. 26), postergando-se, mais uma vez, a correta identificação e reparação dos atingidos para a próxima fase de licenciamento.

No ano de 2012, diversas Ações Civis Públicas impetradas pelo Ministério Público Estadual (MPE) fizeram com que o andamento do empreendimento fosse paralisado. Em razão da pressão feita pelos atingidos para uma visita do MPE na região, foi agendada uma nova audiência pública em abril, que ocorreu na comunidade de São Sebastião do Bom Sucesso. Durante a audiência, foram discutidas mais uma vez as violações que continuavam sem solução e pediu-se que o Ministério Público e a Defensoria Pública tomassem as medidas necessárias, através do protocolo que tomava como base o Relatório do Conselho de Defesa dos Direitos da Pessoa Humana (CDDPH) de 2011 sobre direitos dos atingidos por barragens (PEREIRA; BECKER; WILDHAGEN, 2013). Visto que um ônibus escolar que levaria a comunidade de Jassem para a audiência pública foi "extraviado" durante a noite, fazendo com que o direito de participação dessa comunidade fosse mitigado, foi marcada uma reunião em tal comunidade (MINAS GERAIS, 2012b).

Na reunião pública que ocorreu na região do Jassem, dentre as providências a ser tomadas pelo MPE, arguiu-se que seriam instaurados na Promotoria do Serro e de Conceição do Mato Dentro inquéritos civis para acompanhar e fiscalizar as repercussões socioambientais do 
empreendimento, sem prejuízo de outros inquéritos e ações já ajuizadas. Criou-se também a Rede de Acompanhamento Socioambiental (REASA), que se consistia em um grupo de "representantes de instituições públicas e sociedade civil organizada, que iria se reunir mensalmente para desenvolvimento de questões tratadas na audiência pública” (MINAS GERAIS, 2012a, p. 3).

Através da REASA, reuniões mensais em diversas comunidades foram realizadas ao longo de 2012 até abril de 2013 e recomendações foram enviadas à empresa (PEREIRA; BECKER; WILDHAGEN, 2013). No final de sua atuação, a REASA, além das Ações Civis Públicas que já havia sido instauradas no ano de 2012, contabilizou a formulação de três TAC. Ocorre, porém, que, segundo Prates (2014), a comunidade, de forma geral, não ficou satisfeita com a atuação do MPE, dado que um espaço de discussão sobre os termos dos TAC não foi disponibilizado, passando a instituição a celebrar os termos sem a incorporação das sugestões dos atingidos.

Em 2013, a discussão sobre o relatório da Diversus que restava parado na URC Jequitinhonha voltou à tona. Nesse período, a empresa já havia encomendado outro parecer para a consultora Ferreira Rocha Gestão de Projetos Sustentáveis. O novo relatório apresentado questionava o trabalho anterior e defendia o disposto no EIA/RIMA, alegando, para tanto, que a Diversus teria apenas relatados supostos impactos. Diante de tal situação, na $77^{\mathrm{a}}$ reunião da URC Jequitinhonha, decidiu-se pela feitura de um novo relatório, mais atualizado, porém nenhuma das sugestões fornecidas pelos atingidos ou mesmo pelo GESTA (Grupo de Pesquisa em Temáticas Ambientais da UFMG), que também participava, foi acolhida (GRUPO DE PESQUISA EM TEMÁTICAS AMBIENTAIS DA UFMG, 2016). 
Em abril de 2014, a dinâmica do REASA foi oficialmente extinta de acordo com a vontade dos atingidos, uma vez que, a seu ver, a existência do REASA pouco ou nada contribuiu com a situação da população. Assim, de forma independente, os atingidos criaram a Rede de Articulação e Justiça Ambiental dos Atingidos pelo Projeto Minas-Rio (REAJA) para seguir com as demandas (ZUCARELLI; SANTOS, 2014).

Após a demonstração do novo estudo da Diversus às comunidades atingidas, em agosto de 2014, questionou-se mais uma vez a metodologia utilizada pelo estudo e aprovada pela URC Jequitinhonha, principalmente quanto à falta de um trabalho de campo etnográfico e a carência de informações sobre a descrição das comunidades, além da não inclusão de diversas famílias na lista. No mês de setembro, a Licença de Operação do mineroduto foi concedida pelo IBAMA, o que, mais uma vez, pressionou a liberação da Licença de Operação da mina e de suas estruturas adjacentes. O parecer único da SUPRAM quanto a essa licença da mina trazia as diversas condicionantes que não foram cumpridas pela empresa, como a aprovação prévia do novo estudo da Diversus em conselho da URC, a fim de finalmente definir o universo de famílias atingidas. Em setembro de 2014 uma nova reunião foi realizada e em sua pauta estava novamente a discussão da Licença de Operação da mina. Após 12 horas de duração, muitos conflitos, principalmente entre os atingidos presentes e funcionários da empresa e inúmeros questionamentos feitos pelo MPE, por acadêmicos e por representantes das comunidades, a Licença de Operação foi concedida (PRATES, 2014).

Percebe-se ao longo dos fatos aqui relatados que ambas as injustiças por mau enquadramento e por falsa-representação políticacomum são verificadas durante a instalação do empreendimento. Comunidades inteiras foram ignoradas pela empresa tanto na produção 
do EIA/RIMA, quanto na complementação de cadastro dos atingidos, como pôde se averiguar através da análise feita pela Diversus. Aqueles que foram considerados atingidos não se beneficiaram de voz ativa o suficiente em relação aos outros atores, a fim de se discutir, como pares, como seria a solução para as injustiças ali detectadas.

Nesse sentido, é de grande valia discutir o relacionamento triangular entre a empresa, os atingidos e o órgão ambiental: a falsa representação da política comum e o mau enquadramento surgem na própria gênese de tal relação. Primeiramente, é durante o EIA/RIMA que os atingidos são ou deveriam ser identificados. Esse estudo é contratado e pago pela própria empresa que, manifestamente, possui interesse em que ele seja positivo e demonstre o menor número de problemas.

Além disso, salienta-se que as audiências públicas, segundo a legislação vigente e já aqui discutida não são obrigatórias durante a produção do EIA e consequente identificação dos atingidos e, tampouco, durante o processo de licenciamento, sendo elas programadas apenas nos casos acima dispostos. Mesmo nos casos em que há audiência pública, como no caso em estudo, deve-se discutir, também, a eficácia desse meio de participação popular em relação à quantidade de pessoas que dela participam e à real importância desprendida ao que é descrito pelos atingidos.

Os órgãos ambientais possuem também responsabilidade pelas violações, principalmente pelo fato de concederem licenças sem que todos os atingidos fossem de fato ouvidos e identificados, sem que as condicionantes tivessem sido cumpridas e sem que medidas mitigadoras tivessem sido avaliadas o que é vedado pela Resolução no 237 de 1997 do CONAMA (CONAMA, 1997).

Percebe-se, portanto, que, mais do que de conteúdo, o problema 
que aqui se instaura tem origem na forma com que as discussões de justiça vêm sendo travadas, o que leva à descoberta do "como" da justiça. Esse parâmetro diz respeito ao fracasso de se institucionalizar a paridade de participação em deliberações sobre o "quem” da justiça (que, segundo Fraser, deveria levar em conta o princípio de todos os afetados) e se relaciona ao método utilizado para se discutir o novo enquadramento. Isso demonstra que, se as injustiças de segunda ordem não forem reparadas em primeiro lugar, dificilmente as de reivindicações por redistribuição e reconhecimento o serão.

Ao longo do trabalho confirmou-se que a paridade participativa deve ser o parâmetro para a persecução da justiça, em todas as suas dimensões. Porém, quando se falha em estabelecer este parâmetro, como o que é verificado no caso concreto, Nancy Fraser (2009) defende que a luta por justiça, em todas as suas dimensões, não pode estar apartada de uma luta por democracia metapolítica, ou seja, de uma luta por iguais condições de influência e participação na definição do próprio enquadramento.

\section{CONSIDERAÇÕES FINAIS}

No decorrer do trabalho, através de um estudo de caso do eixo minerário do Projeto Minas-Rio, foi possível dar o primeiro passo em direção a uma teoria sobre o processo de identificação de atingidos no Brasil, principalmente no que se refere à justiça do paradigma atual. O modelo de análise aqui realizado, ao ser replicado em outros casos de violações de direitos humanos por empreendimentos minerários, pode ajudar a detectar padrões de comportamento neste tipo de empreendimento. 
Utilizou-se a teoria da justiça de Nancy Fraser como marco teórico e subsumiram-se as violações de direitos humanos ocorridas ao longo da instalação do empreendimento em cada uma das dimensões trazidas pela autora, a fim de que se verificasse quem são realmente os atingidos e quais as suas dificuldades em ter suas pretensões advindas deste estado reconhecidas. Confirmou-se que injustiças das três dimensões foram encontradas durante a instalação do empreendimento e que as injustiças políticas, ou seja, as de segunda ordem (metainjustiças) podem estar obstruindo a reparação das injustiças de primeira ordem, já que se relacionam ao "quem" e ao "como" da justiça. Em outras palavras, no caso concreto, algumas pessoas foram excluídas da discussão sobre justiça de primeiro grau (redistribuição e reconhecimento) e outras não usufruíram de paridade participativa em relação aos outros atores envolvidos na discussão sobre essas violações e possíveis mitigações.

A hipótese apresentada pelo trabalho foi, então, confirmada, tendo sido o processo de identificação de atingidos no Projeto MinasRio injusto, segundo o marco teórico. A identificação de atingidos e as reparações sugeridas pelo EIA/RIMA não foram suficientes para abarcar todo o universo de pessoas que de alguma forma foram afetadas pelo empreendimento, o que gerou a não reparação de violações de direitos humanos e, consequentemente, diversas injustiças que, ao longo da instalação, foram reforçadas pela atuação parcial dos órgãos ambientais.

Através desse diagnóstico, percebe-se que a construção de um ambiente político mais favorável para a discussão da justiça em empreendimentos minerários se mostra urgente, a fim de que tais violações possam ser não apenas reparadas, mas, principalmente prevenidas. Ademais, com a análise futura de outros casos de violação de direitos humanos por empreendimentos minerários e a possível 
identificação de um padrão de comportamento que se encaixa dentro da lógica neoextrativista vivida hoje pela América Latina, será possível a definição de uma teoria em relação ao processo de identificação de atingidos por empreendimentos minerários no Brasil e o questionamento do modelo atual.

\section{REFERÊNCIAS}

BARCELOS, Eduardo (Coord.). O projeto Minas Rio e seus impactos socioambientais: olhares desde a perspectiva dos atingidos: relatório preliminar. 2014. Disponível em: $<$ https://agburbana.files. wordpress.com/2014/03/dossic3aa-minas-rio-final.pdf $>$. Acesso em: 5 jul. 2017.

BECKER, Luzia Costa; PEREIRA, Denise de Castro. O projeto Minas-Rio e o desafio do desenvolvimento territorial integrado e sustentado: a grande mina em Conceição do Mato Dentro. Recursos Minerais \& Sustentabilidade Territorial, Rio de Janeiro, v. 1, p. 229-258, 2011.

BRASIL. Ministério do Meio Ambiente. Caderno de licenciamento ambiental. Brasília, 2009. Disponível em: $<$ http://www.mma.gov. br/estruturas/dai_pnc/_arquivos/pnc_caderno_licenciamento_ ambiental_01_76.pdf $>$. Acesso em: 15 ago. 2016.

COELHO, Tádzio Peters. Projeto grande Carajás: trinta anos de desenvolvimento frustrado. Marabá: iGuana, 2015.

CONAMA. Resolução $\mathbf{n}^{0} 001$, de 23 de janeiro de 1986. Disponível em: $<$ http://www.mma.gov.br/port/conama/res/res86/res0186.html $>$. Acesso em: 25 jun. 2017.

CONAMA. Resolução nº 009, de 03 de dezembro de 1987.

Disponível em: <http://www.mma.gov.br/port/conama/res/res87/res0987. 
html>. Acesso em: 25 jun. 2017.

CONAMA. Resolução no 237 , de 19 de dezembro de 1997. Disponível em: <http://www.mma.gov.br/port/conama/res/res97/res23797.html>. Acesso em: 25 jun. 2017.

DIVERSUS. Diagnóstico socioeconômico da área diretamente afetada e da área de influência direta do empreendimento Anglo Ferrous Minas-Rio Mineração S.A. 2011.

FRASER, Nancy. Da redistribuição ao reconhecimento? dilemas da justiça numa era "pós-socialista" Tradução de Julio Assis Simões. Cadernos de Campo, São Paulo, v. 14, p. 231-239, 2006.

FRASER, Nancy. Reenquadrando a justiça em um mundo globalizado. Tradução de Ana Carolina Freitas Lima Ogando e Mariana Prandini Fraga Assis. Lua Nova, São Paulo, v. 77, p. 11-39, 2009.

FRASER, Nancy; HONNETH, Axel. Redistribution or recognition? a political-philosophical exchange. London: Verso, 2003.

GRUPO DE PESQUISA EM TEMÁTICAS AMBIENTAIS DA UFMG - GESTA. Conflito e resistência à instalação e operação da mina e do mineroduto do Projeto Minas-Rio. Belo Horizonte, 2016. Disponível em: <http://conflitosambientaismg.lcc.ufmg.br/ conflito/?id=582>. Acesso em: 21 set. 2016.

GUSTIN, Miracy Barbosa de Sousa (Coord.). Cidade e alteridade. Belo Horizonte. 2015. Disponível em: $<$ http://www.cidadeealteridade. com.br/2016/05/relatorio-impactos-da-mineracao-2015/> Acesso em: 28 out. 2016.

MILANEZ, Bruno; SANTOS, R. S. P. Neoextrativismo no Brasil? Uma análise da proposta do novo marco legal da mineração. Revista Pós Ciências Sociais, São Luís, v. 10, p. 119-148, 2013. 
MINAS GERAIS. Ministério Público. Ata da audiência pública realizada no dia 17 de abril de 2012 . Conceição do Mato Dentro, 2012a.

MINAS GERAIS. Ministério Público. Ata da reunião pública realizada no dia 17 de maio de 2012. Alvorada de Minas, 2012 b.

MINAS GERAIS. Sistema Estadual do Meio Ambiente. Anglo Ferrous Minas-Rio Mineração S.A: parecer único no 001/2008. Disponível em: <http://200.198.22.171/down. asp?x_caminho=reunioes/sistema/arquivos/material $/ \& x_{-}$ nome $=4.1 \_$__00472_2007_001_2007_Anglo_Ferrous_Minas-Rio_ Minera\%E7\%E3o_S.A._-_PU.pdf>. Acesso em: 25 jul. 2017.

PEREIRA, Denise de Castro; BECKER, Luzia Costa; WILDHAGEN, Raquel Oliveira. Comunidades atingidas por mineração e violação dos direitos humanos: Cenários em Conceição do Mato Dentro. Revista Ética e Filosofia Política, Juiz de Fora, v. 1, n. 16, p. 124-150, 2013.

\section{PRATES, Clarissa Godinho. Mineração em Conceição do Mato} Dentro: uma análise da REASA como instância de "resolução" de conflitos. 2014. 80 f. Trabalho de Conclusão de Curso (Graduação em Ciências Socioambientais) - Faculdade de Filosofia e Ciências Humanas, Belo Horizonte, 2014.

VAINER, Carlos Bernardo. Conceito de "atingido": uma revisão do debate e diretrizes. Rio de Janeiro, 2003.

YIN, Robert. Estudo de caso: planejamento e métodos. 3. ed. Porto Alegre: Bookman, 2005.

ZHOURI, Andréa. Justiça ambiental, diversidade cultural e accountability: desafios para a governança ambiental. Revista Brasileira de Ciências Sociais, São Paulo, v. 23, p. 97-107, 2008.

ZUCARELLI, Marcos Cristiano; SANTOS, Ana Flávia Moreira. Entre 
a negociação e a resistência: ambiguidades e limites da participação no licenciamento ambiental do complexo minerário Minas-Rio. In: REUNIÃO BRASILEIRA DE ANTROPOLOGIA, 23., 2014, Natal. Anais... Natal: UFRN, 2014.

Como citar: FERNANDES, Elora Raad; NEGRI, Sergio Marcos Carvalho de Ávila. Reivindicações por justiça e a identificação de atingidos no eixo minerário do projeto Minas-Rio. Scientia Iuris, Londrina, v. 22, n. 1, p.37-73, mar. 2018. DOI: 10.5433/2178-8189.2018v22n1p37. ISSN: 2178-8189.

Recebido em: 17/08/2017

Aprovado em: 28/11/2017 